\title{
Incidental cancer in elderly versus younger patients underwent laparoscopic and open cholecystectomy: A retrospective analysis of 2389 patients
}

\author{
(1) Ufuk Uylaş, ${ }^{1}$ ㄴ) Ramazan Gündoğdu² \\ 'Department of General Surgery İmir SBÜ Tepecik Training and Research Hospital, İzmir, Turkey ${ }^{2}$ Department \\ of General Surgery, Başkent University Adana Dr. Turgut Noyan Training and Research Hospital,
}

\begin{abstract}
Introduction: Routine histopathological examination allows the detection of incidental gallbladder cancers. In the present study, we aimed to determine the rate of incidental gallbladder cancer and other pathology outcomes in young and elderly patients who underwent laparoscopic and open cholecystectomy.

Materials and Methods: Patients who underwent laparoscopic and open cholecystectomy in the acute or elective period in our center were retrospectively analyzed. A total of 2389 patients were included in the study. The patients were divided into two groups, as the younger ( $<60$ years old) and elderly ( $\geq 60$ years old).

Results: Of all patients, 476 (19.9\%) were male and 1913 (80.1\%) were female; the mean age was 46 years (range 17-90). There were 486 patients in the elderly group (18.7\%). Chronic cholecystitis was detected in 2228 patients, acute cholecystitis in 141, Xanthogranulomatous cholecystitis in eight, gangrenous cholecystitis in six, and follicular cholecystitis and adenocarcinoma in three patients each. Chronic cholecystitis was more common in the young group, while acute cholecystitis was more common in the elderly group $(p<0.05)$. Adenocarcinoma was detected in three patients $(0.13 \%)$, all of whom were in the elderly group $(p<0.05)$.

Conclusion: Acute or chronic cholecystitis accompanied by a thickened gallbladder wall and a prolonged history of gallstones may be accompanied by malignancy, especially in elderly patients.

Keywords: Cholecystectomy; cholecystitis; cholelithiasis; histopathology; laparoscopy.
\end{abstract}

\section{Introduction}

Gallstones may be seen at any age, but their incidence increases with age, and after 80 years old, $50 \%$ of patients have gallstones. ${ }^{[1]}$ In the presence of benign disease such as symptomatic stones in the gallbladder, laparoscopic cholecystectomy is used as primary treatment. It is believed that the prolonged presence of gallstones in the gallbladder may cause gallbladder cancer. ${ }^{[2]}$ While the incidence of gallstones is between $10-15 \%$ in adults, gallbladder cancer develops in only $0.5 \%$ of these in a 20 -year period. ${ }^{[3]}$ The association of gallbladder cancers with gallstones and chronic cholecystitis has also been reported. ${ }^{[4]}$ Gallbladder cancer is more common in the elderly and in women. ${ }^{[5]}$ The fact that gallbladder cancer takes time to develop and the fact that gallstones are more common in women support these views.

Although not required by the guidelines, the gallbladder specimen is typically sent to pathology department postoperatively. ${ }^{[6]}$ The routine histopathological examination allows for the detection of incidental gallbladder cancers. 
${ }^{[7]}$ However, the incidence of gallbladder cancer is detected as a result of histopathological examination during and after laparoscopic cholecystectomy is quite low and has been reported to be at a rate of $0.3-0.9 \%{ }^{[8]}$ The necessity of routine histopathological examination of cholecystectomy specimens is therefore controversial. The increasing number of laparoscopic cholecystectomy procedures, studies have reported that routine pathological examination presents a burdensome increase in cost, pathologist workload, and lost time. ${ }^{[9]}$

Early diagnosis and surgical treatment of gallbladder cancer provides increased odds of long-term survival and remission. ${ }^{[10]}$ Despite advances in radiological imaging, it is not yet possible to diagnose gallbladder cancer early. Therefore, it is believed that cholecystectomy specimens should be routinely sent for histopathological examination, and in our clinic that is routine practice. We aimed to determine the rate of incidental gallbladder cancer detected by pathology in sequential patients undergoing cholecystectomy for benign causes in our center, and whether this differs from in the pathology results of elderly patients reported in the literature.

\section{Materials and Methods}

Patients who underwent laparoscopic and open cholecystectomy in the acute or elective period between January 2016 and February 2020 at Gaziantep Dr. Ersin Arslan Training and Research Hospital were retrospectively screened. This study was approved by the Gaziantep University Ethical Community (2020/176) and registered in an international database (ClinicalTrials.gov NCT04352478). Data from 2408 patients were obtained. Cholecystectomies with data deficit, performed incidentally, or due to trauma or malignancy were excluded from the study. A total of 2389 patients who underwent acute and elective cholecystectomy were included in the study. Gender, age, method of operation, the timing of the operation, surgical notes, and pathology results were analyzed. As recommended by the World Health Organization (WHO), we divided patients into two groups: elderly ( $\geq 60$ years of age) and younger $(<60 \text { years of age })^{[11,12]}$

\section{Statistical Analysis}

Statistical analyses were performed using SPSS v22.0 software (IBM, Armonk, NY, USA). Quantitative variables were expressed as mean $\pm S D$, median, min-max, and intervals. Qualitative variables were reported as numbers and percentages (\%). The Shapiro-Wilk test was used to assess the normality of the distribution of quantitative variables. While means and standard deviations are used for homogenous distributions, medians and ranges are provided for heterogeneous distributions. Fisher's Chi-Square test was used to compare qualitative variables. The Mann-Whitney $\mathrm{U}$ test was used for heterogeneous distributions, and Student's t-test was used for homogeneous distributions. A p-value below 0.05 was considered statistically significant.

\section{Results}

A total of 2389 patients were included in the study and analyzed. Of these, 476 (19.9\%) of the patients were male and 1913 (80.1\%) were female. The age distribution of the patients was not homogeneous (Shapiro-Wilk test, $\mathrm{p}<0.05$ ) and the median age was 46 (17-90). The majority of the patients were between 41 and 50 years old, and the number of young patients was higher, as 486 patients (18.7\%) were in the elderly patient group (Table 1).

Table 1. Demographic characteristics of patients undergoing cholecystectomy

\begin{tabular}{|c|c|c|}
\hline \multirow[t]{2}{*}{ Characteristics } & $\mathbf{n}$ & $\%$ \\
\hline & \multicolumn{2}{|c|}{ Median (range) } \\
\hline Total patients & \multicolumn{2}{|c|}{2389} \\
\hline \multicolumn{3}{|l|}{ Gender } \\
\hline Male & 476 & 19.9 \\
\hline Female & 1913 & 80.1 \\
\hline \multicolumn{3}{|l|}{ Age } \\
\hline Total patients & 46 & $17-90$ \\
\hline Male & 50 & $19-86$ \\
\hline Female & 46 & $17-90$ \\
\hline \multicolumn{3}{|l|}{$\begin{array}{l}\text { Distribution of } \\
\text { patients by age }\end{array}$} \\
\hline$<20$ & 17 & 0.7 \\
\hline $20-29$ & 306 & 12.8 \\
\hline $30-39$ & 492 & 20.6 \\
\hline $40-49$ & 551 & 23.1 \\
\hline $50-59$ & 537 & 22.5 \\
\hline$\geq 60$ & 486 & 20.3 \\
\hline \multicolumn{3}{|l|}{$\begin{array}{l}\text { Surgical timing } \\
\text { and approach }\end{array}$} \\
\hline Elective & 2351 & 98.4 \\
\hline Emergency & 38 & 1.6 \\
\hline Laparoscopic & 2296 & 96.1 \\
\hline Open & 39 & 1.6 \\
\hline Conversion to open & 54 & 2.3 \\
\hline
\end{tabular}


Elective surgeries comprised $2351(98.4 \%)$ of the operations, while $38(1.6 \%)$ were performed emergently. The majority of the operations (2296, or $96.1 \%$ ) were performed laparoscopically. Open cholecystectomy was performed in 39 patients, and 54 patients underwent conversion to open surgery (COS). Most patients undergoing COS were elective surgeries, as COS was performed emergently in four patients (10.5\%). COS was performed in 28 patients $(5.8 \%)$ in the elderly group, a significantly higher rate than in the younger group $(\mathrm{p}<0.001)$.

Failure to demonstrate the anatomy was the most common reason (in 47 patients, 87\%) for COS being performed. Other causes were ranked according to frequency as follows: cystic duct or biliary tract injury in three cases, perforation in two, and bleeding and hepatic artery injury in one case each.

Chronic cholecystitis was detected in 2228 patients (92.3\%), acute cholecystitis in 141 (5.9\%), Xanthogranulomatous cholecystitis in $8(0.3 \%)$, gangrenous cholecystitis in $6(0.3 \%)$, and follicular cholecystitis and adenocarcinoma in $3(0.1 \%)$ patients each. Other concomitant histopathology results were as follows, ranked according to frequency: Cholesterol polyp in 64 cases $(2.7 \%)$, antral metaplasia in $60(2.5 \%)$, intestinal metaplasia in 15
$(0.6 \%)$, adenomymatosis in $12(0.5 \%)$, foreign-body reaction in $8(0.3 \%)$, focal hyperplasia in $4(0.2 \%)$, Rokitansky-Aschoff sinuses in $3(0.1 \%)$, fibroepithelial polyp in 2 $(0.1 \%)$, low-grade dysplasia in $2(0.1 \%)$ and ectopic liver in one case $(0.04 \%)$.

Histopathological findings were compared in the younger group versus the elderly group (Table 2 ). The histopathology results of the elderly group were ranked according to frequency as follows: chronic cholecystitis in 428 patients (88.1\%), acute cholecystitis in 46 (9.5\%), gangrenous cholecystitis in $4(0.8 \%)$, follicular cholecystitis and adenocarcinoma in three each $(0.6 \%)$, and Xanthogranulomatous cholecystitis in $2(0.4 \%)$. All adenocarcinoma patients were in the elderly group ( $0.6 \%$ vs. $0 \%, p=0.008)$. Chronic cholecystitis was less common in the elderly group, while acute cholecystitis and gangrenous cholecystitis were more common ( $\mathrm{p}<0.05)$.

Data about the histopathological wall thickness of the gallbladder were not available from 36 patients. Of the remainder, there were 2159 patients with wall thickness $<0.6$ $\mathrm{mm}$ and 194 patients with wall thickness $\geq 0.6 \mathrm{~mm}$. The majority of those with a wall thickness of $\geq 0.6 \mathrm{~mm}$ had chronic cholecystitis, detected in 110 of these patients. Other diagnoses included acute cholecystitis in 72, Xan-

\section{Table 2. Histopathological features of both groups}

\begin{tabular}{|c|c|c|c|c|c|}
\hline Pathology diagnoses & $<60$ years $(n=1903)$ & $\%$ & $\geq 60$ years $(n=486)$ & $\%$ & $\mathbf{p}$ \\
\hline Chronic cholecystitis & 1800 & 94.6 & 428 & 88.1 & $<0.001$ \\
\hline Acute cholecystitis & 95 & 4.9 & 46 & 9.5 & $<0.001$ \\
\hline Xanthogranulomatous cholecystitis & 6 & 0.3 & 2 & 0.4 & 0.66 \\
\hline Gangrenous cholecystitis & 2 & 0.1 & 4 & 0.8 & 0.01 \\
\hline Follicular cholecystitis & 0 & 0 & 3 & 0.6 & $<0.001$ \\
\hline Adenocarcinoma & 0 & 0 & 3 & 0.6 & $<0.001$ \\
\hline \multicolumn{6}{|l|}{ Other concomitant pathology diagnoses } \\
\hline Cholesterol polyp & 54 & 2.8 & 10 & 2.1 & 0.43 \\
\hline Antral metaplasia & 46 & 2.4 & 14 & 2.9 & 0.52 \\
\hline Intestinal metaplasia & 10 & 0.5 & 5 & 1 & 0.21 \\
\hline Adenomymatozis & 11 & 0.5 & 1 & 0.2 & 0.48 \\
\hline Foreign body reaction & 6 & 0.3 & 2 & 0.4 & 0.67 \\
\hline Focal hyperplasia & 4 & 0.2 & 0 & 0 & 0.59 \\
\hline Rokitansky-Aschoff sinuses & 2 & 0.1 & 1 & 0.2 & 0.49 \\
\hline Low-grade dysplasia & 2 & 0.1 & 0 & 0 & 1.00 \\
\hline Fibroepithelial polyp & 1 & 0.05 & 0 & 0 & 1.00 \\
\hline Tubular adenoma & 0 & 0 & 1 & 0.2 & 0.20 \\
\hline Ectopic liver & 1 & 0.05 & 0 & 0 & 1.00 \\
\hline
\end{tabular}


thogranulomatous cholecystitis in five, gangrenous cholecystitis in four, adenocarcinoma in two, and follicular cholecystitis in one patient. Patients with wall thickness with $\geq 0.6 \mathrm{~mm}$ were significantly more common in the elderly patient group ( $11.5 \%$ vs. $7.4 \%, \mathrm{p}=0.005)$. Among acute cholecystitis patients, the detection rate of wall thickness $\geq 0.6 \mathrm{~mm}$ was higher ( $55.8 \%$ vs. $5 \%$, $\mathrm{p}<0.001$ ).

A polyp was detected in the histopathology results of 66 $(2.8 \%)$ patients, more commonly in the younger patient group ( $2.9 \%$ vs $2.3 \%, \mathrm{p}=0.54)$. The polyps detected were all cholesterol polyps (64 cases) except one fibroepithelial polyp and one tubular adenoma. Cholesterolosis was detected in 368 patients (15.4\%) and was more common among women and patients in the younger group $(\mathrm{p}<0.05)$. Cholesterol polyp was more common in the younger group patients ( $p>0.05$ ). In 27 of 36 patients with polyps detected in preoperative hepatobiliary ultrasonography, there were multiple polyps, and the average size of the polyps found was $3 \mathrm{~mm}(1 \mathrm{~mm}-10 \mathrm{~mm})$.

Adenocarcinoma was detected in $3(0.13 \%)$ patients, all of whom were in the elderly group ( $0.6 \%$ vs. $0 \%, \mathrm{p}=0.008)$. No polyp was seen in the preoperative ultrasonography of two patients with adenocarcinoma, and the findings were compatible with acute cholecystitis. These two patients underwent open or COS cholecystectomy. The other patient underwent elective laparoscopic cholecystectomy. In additional pathological findings, polyp, stone, and stone together with the polyp were detected in one patient (Table 3 ).

\section{Discussion}

Gallstones and chronic cholecystitis are implicated in the etiology of gallbladder cancer. ${ }^{[13-15]}$ Gallstones that reside in the gallbladder for a long time can cause gallbladder cancer by causing chronic cholecystitis. Cholelithiasis is present in $75-92 \%$ of gallbladder cancers. ${ }^{[16]}$ In a routine histopathological examination of the gallbladder, chronic cholecystitis is detected in the rate of $89-96.3 \% \cdot{ }^{[7,8]}$ In our study, chronic cholecystitis constituted $92.7 \%$ of pathological findings. Chronic cholecystitis was significantly less common in the elderly group $(\mathrm{p}<0.001)$, which may be due to the smaller number in the elderly patient group.

If the polyp detected in the gallbladder is $>10 \mathrm{~mm}$, sessile, single, and rapidly growing, it should raise suspicion of malignancy, ${ }^{[17]}$ especially for polyps $>15 \mathrm{~mm}$, for which the risk is higher, with cancer incidence reported at $45 \%{ }^{[18,19]}$ In our study, 66 patients $(2.8 \%)$ had polyps, and most of which were cholesterol polyps (97\%). The polyp detection rate was higher in the younger group $(p=0.54)$. Incidental polyps were detected in 30 patients (45.5\%), with an average size of $3 \mathrm{~mm}(1 \mathrm{~mm}-30 \mathrm{~mm})$. In the final pathology report of two patients with an incidental polyp, adenocarcinoma was detected; the polyp sizes were $10 \mathrm{~mm}$ and $30 \mathrm{~mm}$. No polyp was seen in the preoperative hepatobiliary ultrasonography of two patients with adenocarcinoma, and the findings were compatible with acute cholecystitis.

Hyperplasia and atypical epithelial lesions may be the cause of gallbladder cancer ${ }^{[20]}$ It has been described that intestinal metaplasia can progress to dysplasia and carcinoma, respectively. ${ }^{[21]}$ Although metaplasia generally develops in the atrophic mucosa, when mucosal hyperplasia is stained, the metaplastic tissue also thickens. Therefore, the presence of hyperplasia along with metaplasia should be demonstrated. ${ }^{[22]}$ In our series, atypical epithelial lesions were detected in 81 patients (3.4\%). In this group, antral metaplasia was detected in 60 cases $(74.1 \%)$, intestinal metaplasia in $15(18.5 \%)$, focal hyperplasia in 4 (4.9\%), and low-grade dysplasia in $2(2.5 \%)$ patients. Intestinal metaplasia and antral metaplasia were more common in the elderly patient group ( $p>0.05$ ). There was no metaplasia associated with focal mucosal hyperplasia,

Table 3. Patients with incidental malignancy

\begin{tabular}{lccc} 
Patients & Adenocarcinoma & Adenocarcinoma & Adenocarcinoma \\
\hline Age & 73 & 69 & 66 \\
Gender & Male & Female & Female \\
Operation & Open & Conversion & Laparoscopy \\
Operation timing & Emergency & Elective & Elective \\
Stage & T1bNOM0 & T1bNOM0 & T1aNOM0 \\
Concomitant pathology & Cholelithiasis & Cholelithiasis + Polyp & Tubuler adenoma \\
Outcome & Exitus & Live (11 months) & Live (8 months)
\end{tabular}


but the low-grade dysplasia cases were concomitant with intestinal metaplasia.

Preoperative diagnosis of gallbladder cancer and its depth of invasion are not easy to assess. Lesions such as Xanthogranulomatous cholecystitis and adenomyomatosis are difficult to differentiate from gallbladder cancer ${ }^{[23,24]}$ It has been reported that laparoscopic cholecystectomy may cause cancer spillage and worsen its prognosis in cases where the presence of gallbladder cancer is undetected before the pathological examination. ${ }^{[25]}$ For this reason, an intraoperative frozen section evaluation is recommended to understand the presence of gallbladder cancer in patients with increased wall thickness, those over 70 years of age, those with a long history of stones, and patients with suspected polyps. ${ }^{[26]} \mathrm{COS}$ is recommended to if gallbladder cancer is observed during laparoscopic cholecystectomy ${ }^{[27]}$ Because extensive surgical resection increases the odds of cancer spillage, it is recommended that inexperienced operators refer the case to a tertiary care center instead of proceeding. ${ }^{[28]}$ In all three patients with adenocarcinoma in our study, an intraoperative frozen section evaluation was not needed because there was no suspicion of malignancy before or during surgery.

Especially as centers increase their laparoscopic experience, laparoscopic cholecystectomy is increasingly performed in acute cholecystitis cases. Patients with gallbladder cancers often experience attacks of acute cholecystitis. ${ }^{[29]}$ In these cases, emptying the gallbladder to facilitate the procedure may cause cancer to spread by spilling bile, worsening prognosis. ${ }^{[30]}$ For this reason, older publications especially recommended that elderly patients presenting with acute cholecystitis and the possibility of gallbladder cancer continue with open surgery to prevent bile spillage. Despite this, there are publications reporting identical survival in open and laparoscopic gallbladder cancer surgery. ${ }^{[31]}$ Open surgery was performed in two of the three patients with adenocarcinoma in our study. One of the patients had a direct open operation due to a perforation, and in the other patient the COS was applied because the anatomy could not be demonstrated.

The limitations of this study are retrospective analysis and a relatively limited number of patients. It may also be a limitation that the study was conducted only in one center. In the literature, it has been reported that the incidence of gallbladder cancer increases in older age. In our study, all of them were detected in elderly patients in line with the literature.

\section{Conclusion}

It should be remembered that malignancy is more frequently accompanied, especially in elderly patients with long-term exist gallstones, acute or chronic cholecystitis symptoms accompanied by increased wall thickness.

\section{Disclosures}

Ethichs Committee Approval: This study was approved by the Gaziantep University Ethical Community (2020/176) and registered in an international database (ClinicalTrials.gov NCT04352478).

Peer-review: Externally peer-reviewed.

Conflict of Interest: None declared.

Authorship Contributions: Concept - U.U., R.G.; Design - U.U.; Supervision - U.U.; Materials - U.U., R.G.; Data collection and/or processing - U.U., R.G.; Analysis and/ or interpretation - U.U., R.G.; Literature search - U.U., R.G.; Writing - U.U., R.G.; Critical review - U.U., R.G.

\section{References}

1. Coelho JCU, Dalledone GO, Domingos MF, Nassif LT, de-Freitas ACT, Matias JEF. Results of laparoscopic cholecystectomy in the elderly. Rev Col Bras Cir 2018;45:e2020. [CrossRef]

2. Zatonski WA, Lowenfels $A B$, Boyle $P$, Maisonneuve $P$, Bueno de Mesquita HB, Ghadirian $P$, et al. Epidemiologic aspects of gallbladder cancer: a case-control study of the SEARCH Program of the International Agency for Research on Cancer. J Natl Cancer Inst 1997;89:1132-8. [CrossRef]

3. Randi G, Franceschi S, La Vecchia C. Gallbladder cancer worldwide: geographical distribution and risk factors. Int $\mathrm{J}$ Cancer 2006;118:1591-602. [CrossRef]

4. Gore RM, Yaghmai V, Newmark GM, Berlin JW, Miller FH. Imaging benign and malignant disease of the gallbladder. Radiol Clin North Am 2002;40:1307-23, vi.

5. Hamdani NH, Qadri SK, Aggarwalla R, Bhartia VK, Chaudhuri S, Debakshi S, et al. Clinicopathological study of gall bladder carcinoma with special reference to gallstones: our 8-year experience from eastern India. Asian Pac J Cancer Prev 2012;13:5613-7. [CrossRef]

6. Overby DW, Apelgren KN, Richardson W, Fanelli R; Society of American Gastrointestinal and Endoscopic Surgeons. SAGES guidelines for the clinical application of laparoscopic biliary tract surgery. Surg Endosc 2010;24:2368-86. [CrossRef]

7. Basak F, Hasbahceci M, Canbak T, Sisik A, Acar A, Yucel M, et al. Incidental findings during routine pathological evaluation of gallbladder specimens: review of 1,747 elective laparoscopic cholecystectomy cases. Ann R Coll Surg Engl 2016;98:280-3. [CrossRef]

8. Kim JH, Kim WH, Kim JH, Yoo BM, Kim MW. Unsuspected gallbladder cancer diagnosed after laparoscopic chole- 
cystectomy: focus on acute cholecystitis. World J Surg 2010;34:114-20. [CrossRef]

9. Bazoua G, Hamza N, Lazim T. Do we need histology for a normal-looking gallbladder? J Hepatobiliary Pancreat Surg 2007;14:564-8. [CrossRef]

10. Benoist $\mathrm{S}$, Panis $\mathrm{Y}$, Fagniez PL. Long-term results after curative resection for carcinoma of the gallbladder. French University Association for Surgical Research. Am J Surg 1998;175:118-22. [CrossRef]

11. United Nations, Department of Economic and Social Affairs, Population Division (2017). World Population Ageing 2017 (ST/ESA/SER.A/408).

12. WHO. Health statistics and information systems. Proposed working definition of an older person in Africa for the MDS Project. Available at: http://www.who.int/healthinfo/survey/ ageingdefnolder/en/. Accessed Jan 20, 2021.

13. Hart J, Modan B, Shani M. Cholelithiasis in the aetiology of gallbladder neoplasms. Lancet 1971;1:1151-3. [CrossRef]

14. Akyürek $N$, Irkörücü $O$, Salman $B$, Erdem $O$, Sare $M$, Tatlicioğlu E. Unexpected gallbladder cancer during laparoscopic cholecystectomy. J Hepatobiliary Pancreat Surg 2004;11:357-61.

15. Kesici U, Kesici S, Zeren S, Türkmen ÜA, Çimen M, Burakgazi G. Safra kesesi gastrik metaplazi; olgu sunumu ve literatür değerlendirmesi. Şişli Etfal Hastanesi Tıp Bülteni 2012;46:30-2.

16. Bhattacharjee PK, Nanda D. Prospective observational study on cholelithiasis in patients with carcinoma gall bladder in a tertiary referral hospital of Eastern India. J Cancer Res Ther 2019;15:153-6.

17. Ome $Y$, Hashida K, Yokota M, Nagahisa Y, Okabe M, Kawamoto K. Laparoscopic approach to suspected T1 and T2 gallbladder carcinoma. World J Gastroenterol 2017;23:2556-65.

18. Yeh CN, Jan YY, Chao TC, Chen MF. Laparoscopic cholecystectomy for polypoid lesions of the gallbladder: a clinicopathologic study. Surg Laparosc Endosc Percutan Tech 2001;11:176-81. [CrossRef]

19. Sujata J, $S R$, Sabina $K, M j H$, Jairajpuri ZS. Incidental gall bladder carcinoma in laparoscopic cholecystectomy: a report of 6 cases and a review of the literature. J Clin Diagn Res 2013;7:85-8. [CrossRef]

20. Duarte I, Llanos O, Domke H, Harz C, Valdivieso V. Metaplasia and precursor lesions of gallbladder carcinoma. Frequency, distribution, and probability of detection in routine histologic samples. Cancer 1993;72:1878-84. [CrossRef]

21. Yamagiwa $\mathrm{H}$, Tomiyama $\mathrm{H}$. Intestinal metaplasia-dysplasia-carcinoma sequence of the gallbladder. Acta Pathol Jpn 1986;36:989-97. [CrossRef]

22. Albores-Saavedra J, Nadji M, Henson DE, Ziegels-Weissman J, Mones JM. Intestinal metaplasia of the gallbladder: a morphologic and immunocytochemical study. Hum Pathol 1986;17:614-20. [CrossRef]

23. Deng YL, Cheng NS, Zhang SJ, Ma WJ, Shrestha A, Li FY, et al. Xanthogranulomatous cholecystitis mimicking gallbladder carcinoma: An analysis of 42 cases. World J Gastroenterol 2015;21:12653-9. [CrossRef]

24. Ootani T, Shirai Y, Tsukada K, Muto T. Relationship between gallbladder carcinoma and the segmental type of adenomyomatosis of the gallbladder. Cancer 1992;69:2647-52. [CrossRef]

25. Shirai Y, Ohtani T, Hatakeyama K. Laparoscopic cholecystectomy may disseminate gallbladder carcinoma. Hepatogastroenterology 1998;45:81-2.

26. Contini S, Dalla Valle R, Zinicola R. Unexpected gallbladder cancer after laparoscopic cholecystectomy: an emerging problem? Reflections on four cases. Surg Endosc 1999;13:264-7. [CrossRef]

27. Braghetto I, Bastias J, Csendes A, Chiong H, Compan A, Valladares $\mathrm{H}$, et al. Gallbladder carcinoma during laparoscopic cholecystectomy: is it associated with bad prognosis? Int Surg 1999;84:344-9.

28. Shih SP, Schulick RD, Cameron JL, Lillemoe KD, Pitt HA, Choti MA, et al. Gallbladder cancer: the role of laparoscopy and radical resection. Ann Surg 2007;245:893-901. [CrossRef]

29. Chao TC, Jeng LB, Jan YY, Hwang TL, Wang CS, Chen MF. Concurrent primary carcinoma of the gallbladder and acute cholecystitis. Hepatogastroenterology 1998;45:921-6.

30. Clemente G, Nuzzo G, De Rose AM, Giovannini I, La Torre G, Ardito $F$, et al. Unexpected gallbladder cancer after laparoscopic cholecystectomy for acute cholecystitis: a worrisome picture. J Gastrointest Surg 2012;16:1462-8. [CrossRef]

31. Feng JW, Yang XH, Liu CW, Wu BQ, Sun DL, Chen XM, et al. Comparison of Laparoscopic and Open Approach in Treating Gallbladder Cancer. J Surg Res 2019;234:269-76. [CrossRef] 